Many features of this syndrome could be explained by an underlying myopathy. In congenital fibre type disproportion, short stature, contractures, scoliosis, and high arched palate were reported in a review by Cavanagh et al..$^{6}$ In nemaline myopathy skeletal abnormalities and reduced muscle bulk are well recognised. ${ }^{?}$

Further investigation of muscle function in other patients with this syndrome is likely to be rewarding.

We would like to thank Drs J Wilson and J Payan for their help in investigating this patient, and $\mathrm{Dr} S$ Ware for referring the patient to our clinic. Dr M A Patton is supported by a Child Health Research Fund Fellowship.

\footnotetext{
References

${ }^{1}$ Goodman RM, Katznelson MB. Manor E. Camptodactyly: occurrence in two genetic syndromes and its relationship to other syndromes. J Med Genet 1972:9:203-12.
}

- Goodman RM. Katznelson MB. Hertz M. Katznelson A. Camptodactyly, with muscular hypoplasia, skelctal dysplasia and abnormal palmar creases: Tel Hashomer camptodactyly syndrome. J Med Genet 1976:13:136-41.

${ }^{3}$ Gollop TR. Colletto GMDD. The Tel Hashomer camptodactyly syndrome in a consanguincous Brazilian family. Am J Med Genet 1984:17:399-406.

+ Schaumann B. Alter M. Dermatolglyphics in medical disorders. Chap 5. Berlin: Springer-Verlag. 1976:103-29.

5 Popich GA. Smith DW. The genesis and significance of digital and palmar hand creases: preliminary report. $J$ Pediatr 1970;77:1017-23.

" Cavanagh NPC. Lake BD. McMeniman P. Congenital fibre type disproportion myopathy: a histological diagnosis with an uncertain clinical outlook. Arch Dis Child 1979:54:735-43.

${ }^{7}$ Dubowitz V. Muscle disorders of childhood. Philadelphia: Saunders, 1978 .

Correspondence and requests for reprints to $\mathrm{Dr}$ M A Patton, Department of Clinical Genetics, Institute of Child Health, 30 Guilford Street, London WC1N 1EH.

\title{
A male infant with the Catel-Manzke syndrome and dislocatable knees
}

\author{
E M THOMPSON*, R M WINTER ${ }^{*}$, AND M J H WILliAMS \\ *Clinical Genetics Unit, The Hospital for Sick Children, Great Ormond Street, London WC1N 3JH; \\ †Division of Inherited and Metabolic Disease, Clinical Research Centre, Watford Road, Harrow, Middlesex \\ HAI 3UJ; and $¥$ Department of Paediatrics, Watford General Hospital, Shrodells Wing, Vicarage Road, \\ Watford, Herts WD1 $8 H B$.
}

SUMmary A male infant is described with severe micrognathia and bilateral duplication of the proximal phalanges of the index fingers, an association which is characteristic of the Catel-Manzke syndrome. In addition, he had dislocatable knees, which have not been described in this disorder before.

In 1966, Manzke ${ }^{1}$ described in detail a male infant originally reported by Catel. ${ }^{2}$ The child had the Pierre Robin sequence with micrognathia, cleft palate and glossoptosis, associated with an accessory bone at the base of each index finger. In 1982, Sundaram $e t t^{3}$ presented another similar patient and reviewed seven others from published reports, including the original case. They first used the name Catel-Manzke syndrome to describe the disorder. A patient with the same features was also described by

Received for publication 4 May 1985

Revised version accepted for publication 16 July 1985
Silengo et al. ${ }^{4}$ All patients have been males and five have had congenital heart defects. The inheritance pattern is uncertain, with the suggestion of an affected sib $^{5}$ and of affected family members in three generations. ${ }^{6}$

We present another case, also a male, with significant dislocations of the knees.

\section{Case report}

The patient was born at 35 weeks' gestation by caesarian section because of maternal preeclampsia. The birth weight was $2.0 \mathrm{~kg}$ (3rd to 10 th centile) and no resuscitation was required initially. Abnormalities noted at birth included severe micrognathia, a high arched, but intact palate, and marked pectus excavatum. The index fingers were short and their proximal phalanges were broad and deviated radially (fig 1$). X$-rays revealed two small bones at the base of both index fingers, interpreted as duplication of the proximal phalanges, and shortened second metacarpals and bilateral clino- 


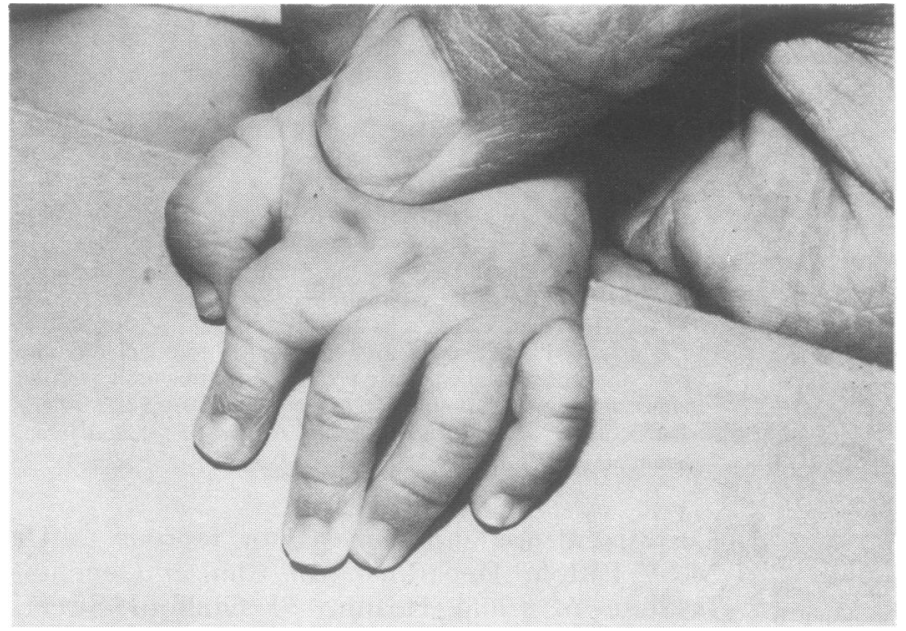

FIG 1 The index finger is short with a broad, radially deviated proximal phalanx.

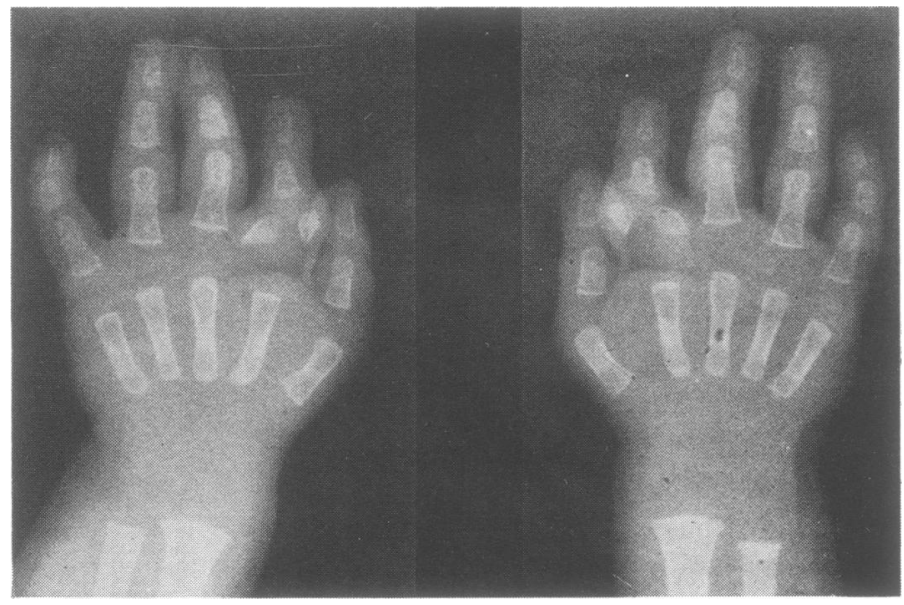

FIG 2 Note duplication of proximal phalanx of both index fingers.

dactyly of the fifth fingers (fig 2). There were no cardiac murmurs and an electrocardiogram and chest $x$-ray were normal. The knees showed a remarkable degree of ligamentous laxity in the anterior-posterior plane. $X$-rays of the femora, tibiae, and feet were normal. The lower femoral epiphyses were only just beginning to ossify at 1 week of age. which indicates some delay in bone maturation. The patellae were present and were not dislocated. The clinical diagnosis of the knee dislocation was congenital absence of the anterior cruciate ligaments. The patient remained in the special care baby unit for five weeks because of severe feeding difficulties, secondary to micrognathia and upper airway obstruction. These symptoms persisted and he failed to thrive.
When seen in the genetic clinic at $31 / 2$ months, the weight was $3.45 \mathrm{~kg}$ (well below the 3 rd centile), the length $53.4 \mathrm{~cm}$ (below the 3rd centile), and head circumference $38.5 \mathrm{~cm}$ (25th centile). The severe micrognathia (figs 3 and 4) and pectus excavatum (25th centile) were still evident, but the respiratory distress had almost resolved.

The instability of the knees was of such a degree that at 8 months a strip of tensor fascia lata was released and transferred to the knee, in an attempt to improve the stability.

The parents were a non-consanguineous English couple. Both had normal hands. The father was aged 47 and the mother 36 years at the time of the child's birth and it was the mother's first pregnancy. The family history was unremarkable. 


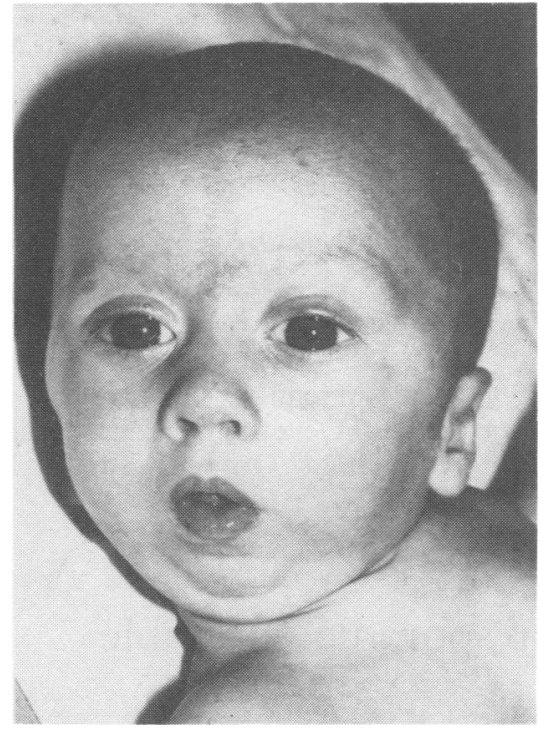

FIG 3 The proband. Note the severe micrognathia.

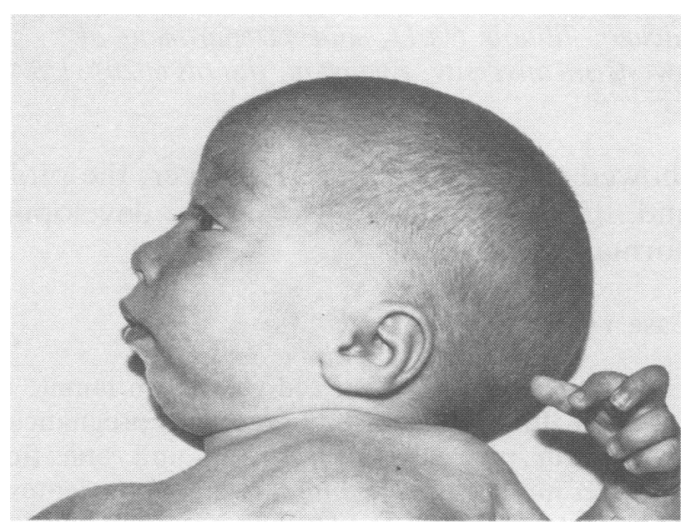

FIG 4 Side view of the proband.

\section{Discussion}

The Catel-Manzke syndrome is characterised by the association of the Pierre-Robin sequence (cleft palate, glossoptosis, and micrognathia) with an accessory proximal phalanx of the index finger bilaterally. Although our patient's palate was intact, the degree of micrognathia and associated upper respiratory obstruction (presumably due to glossop- tosis), together with the typical digital defect, make the diagnosis of the Catel-Manzke syndrome likely. One other case had an intact palate, namely the maternal grandfather of the proband reported by Stevenson et al. ${ }^{6}$ Shortening of the second metacarpal bones has been noted in five others. ${ }^{467}$

Our patient had a significant degree of knee dislocation, possibly due to absence of the anterior cruciate ligaments. Joint abnormalities have not been noted before in the syndrome, apart from two patients with talipes equinovarus, one of whom required surgical correction of the foot deformities. $^{78}$

The pectus excavatum in our case may have been secondary to severe chronic upper airway obstruction. A mild pectus excavatum was noted in the proband described by Stevenson et al. ${ }^{6}$ That child also had a congenital heart defect. The latter have occurred in five of the 10 cases now reported and have been mostly septal defects. ${ }^{3-68}$ Failure to thrive, as in our case, was documented in three others and could be explained by respiratory or cardiac problems or both. ${ }^{58}$ Development is usually normal. One child was mildly developmentally delayed at 15 months. ${ }^{6}$

Most cases of the Catel-Manzke syndrome have been sporadic. Gewitz et $a{ }^{5}$ reported an affected male whose stillborn brother had the Pierre-Robin sequence and an atrial septal defect, but it was not known if he had the typical finger abnormality. It is likely that the latter sib also had the Catel-Manzke syndrome which would suggest autosomal or $\mathrm{X}$ linked recessive inheritance. Consistent with the latter is the fact that all cases have been males. However, in one family, ${ }^{6}$ there may have been male to male transmission of the digital deformity but this was not able to be confirmed.

Lipson et al" described two sibs with cleft palate and bilateral clinodactyly whose mother had untreated hyperphenylalaninaemia. One had unilateral hyperphalangy of the index finger and the other had a congenital heart defect. The former probably had the Catel-Manzke syndrome. The authors' suggestion that hyperphalangy could be a teratogenic result of maternal hyperphenylalaninaemia seems less likely than a fortuitous association of Catel-Manzke syndrome and maternal phenylalanine effect, since hyperphalangy has not been reported in offspring of PKU mothers. ${ }^{10}$

The authors thank Dr Christine Hall, Consultant Radiologist at The Hospital for Sick Children, Great Ormond Street, for helpful discussions, and Mrs Melanie Barham for secretarial asssistance. Dr Thompson is supported by a Wellcome Trust Training Fellowship. 
References

' Manzke H. Symmetrische hyperphalangie des zweiten fingers durch ein akzessorisches metacarpale. Fortschr Rontgenstr 1966; 105:425-7.

2 Catel W. Differentialdiagnose von krankheitssymptomen bei kindern und jugendlichen. Vol 1, 3rd ed. Stuttgart: Thieme, 1961:218-20.

${ }^{3}$ Sundaram V, Taysi K, Hartmann AF, Shackleford GD, Keating JP. Hyperphalangy and clinodactyly of the index finger with Pierre-Robin anomaly: Catel-Manzke syndrome. A case report and review of the literature. Clin Genet 1982;21:407-10.

${ }^{4}$ Silengo MC, Franceschini P, Cerutti A, Fabris C. Pierre Robin syndrome with hyperphalangism-clinodactylism of the index finger: a possible new palato-digital syndrome. Pediatr Radiol 1977;6:178-80.

5 Gewitz M, Dinwiddie R, Yuille T, Hill E, Carter CO. Cleft palate and accessory metacarpal of index finger syndrome: possible familial occurrence. J Med Genet 1978;15:162-3.
- Stevenson RE, Taylor HA, Burton OM, Hearn HB. A digito-palatal syndrome with associated anomalies of the heart, face, and skeleton. J Med Genet 1980;17:238-41.

${ }^{7}$ Holthusen W. The Pierre Robin syndrome: unusual associated developmental defects. Ann Radiol (Paris) 1972;15:253-62.

${ }^{8}$ Farnsworth PB, Pacik PT. Glossoptotic hypoxia and micrognathia - the Pierre Robin sequence reviewed. Clin Pediatr 1971;10:600-6.

9 Lipson A, Beuhler B, Bartley J, et al. Maternal hyperphenylalaninaemia fetal effects. $J$ Pediatr 1984;104:216-20.

${ }^{10}$ Stevenson RE, Huntley CC. Congenital malformations in offspring of phenylketonuric mothers. Pediatrics 1967;40:33-45.

Correspondence and requests for reprints to Dr E M Thompson, Clinical Genetics Unit, The Hospital for Sick Children, Great Ormond Street, London WC1N 3JH.

\section{Outcome after prenatal detection of a sporadic, unstable translocation $\mathrm{t}(5 ; 21)$}

ALICE O MARTIN*, IRWIN BENUCK†, HOWARD S TRAISMAN†, MAURICE S SWANSON , NICKLAS TRAKAS*, KERRY LAING*, BARBARA J ROSINSKY*, JUDITH BEAIRD*, EDWARD S TRAISMAN ${ }^{*}$, SHERMAN ELIAS*, AND JOE LEIGH SIMPSON*

${ }^{*}$ Section of Human Genetics, Department of Obstetrics and Gynecology, Northwestern University Medical School and Northwestern Memorial Hospitals; †Department of Pediatrics, Northwestern University Medical School and Children’s Memorial Hospital, Chicago, Illinois 60611; and $¥$ Department of Biochemistry, Molecular Biology and Cell Biology, Northwestern University, Evanston, Illinois 60201, USA.

SUMmary Amniotic fluid cultures from a 37 year old woman showed a sporadic $46, X X, t(5 ; 21)(5 q$ ter $\rightarrow 5 \mathrm{p} 13$ or $\mathrm{p} 14:: 5 \mathrm{pter} \rightarrow 5 \mathrm{p} 13$ or $\mathrm{p} 14:: 21 \mathrm{p} 12 \rightarrow 21 \mathrm{qter})$ complement. In the majority of metaphases the $5 p$ fragment was attached to the stalks of chromosome 21; however, in $9 \%$ of metaphases, the fragment was loosely attached by a 'thread' and in $6 \%$ it was completely detached. Silver staining and in situ hybridisation with a homologous ribosomal gene probe, which localises to stalk regions (nucleolar organisers, NOR) of human acrocentric chromosomes, failed to show a reciprocal exchange. Prognosis was uncertain because the possibility that the $5 p$ fragment might have been lost in some cell lines could not be excluded. Nonetheless, the parents elected to continue the pregnancy. The translocation was confirmed in blood specimens obtained both at birth and at 1 year of age and

Received for publication 27 July 1985 Accepted for publication 13 August 1985 showed similar instability. However, the proband shows no anomalies and is developing normally at 1 year.

\section{Case report}

The mother was a 37 year old Caucasian female in good health. Her three previous pregnancies resulted in two normal offspring and one first trimester miscarriage. She underwent amniocentesis for prenatal diagnosis at 18 weeks' gestation because of advanced maternal age. Family history was unremarkable except for one paternal uncle of the proband said to be 'slow', and one distant cousin said to have Down syndrome. Records were not available on these two people. Pregnancy had been unremarkable, there were no documented exposures to potential teratogens, and the only drugs taken were iron and vitamins. After the chromosomal aberration (to be described later) was detected in amniotic fluid cultures, detailed ultrasound examinations were performed at 21 and 29 weeks' gestation. There was no evidence of growth retardation or anomalies. Despite the uncertain prognosis, 